\title{
Pt(II) Complexes with Linear Diamines-Part I: Vibrational Study of Pt-Diaminopropane
}

\author{
Ana L. M. Batista de Carvalho, ${ }^{1}$ Sónia M. Fiuza, ${ }^{1}$ John Tomkinson, ${ }^{2}$ \\ Luís A. E. Batista de Carvalho, ${ }^{1}$ and M. Paula M. Marques ${ }^{1,3}$ \\ ${ }^{1}$ Research Unit "Molecular Physical-Chemistry", University of Coimbra, 3000 Coimbra, Portugal \\ ${ }^{2}$ ISIS Facility, The Rutherford Appleton Laboratory, Chilton, Didcot OX11 OQX, UK \\ ${ }^{3}$ Department of Life Sciences, Faculty of Science and Technology, University of Coimbra, \\ Apartado 3046, 3001-401 Coimbra, Portugal
}

Correspondence should be addressed to M. Paula M. Marques, pmc@ci.uc.pt

Copyright (C) 2012 Ana L. M. Batista de Carvalho et al. This is an open access article distributed under the Creative Commons Attribution License, which permits unrestricted use, distribution, and reproduction in any medium, provided the original work is properly cited.

\begin{abstract}
A conformational analysis of the $\mathrm{Pt}(\mathrm{dap}) \mathrm{Cl}_{2}$ complex (dap = 1,3-diaminopropane) was performed by vibrational spectroscopy (FTIR, Raman, and INS), coupled to quantum mechanical methods within the density functional theory (DFT) and effective core potential (ECP) approaches. A complete spectral assignment of the system was achieved, due to the combined use of all available vibrational spectroscopic techniques. A good agreement was found between experimental and theoretical results, as well as with reported data for analogous complexes (e.g., cisplatin).
\end{abstract}

Keywords: Pt(II) complexes, 1,3-diaminopropane, anticancer, INS spectroscopy, Raman spectroscopy, infrared spectroscopy

\section{Introduction}

Since the unexpected discovery of the antitumour properties of cisplatin (cis- $\mathrm{Pt}\left(\mathrm{Cl}_{2}\left(\mathrm{NH}_{3}\right)_{2}\right)$ by Rosenberg et al. [1, 2], platinum(II) complexes have become of increasing importance for the design of new anticancer drugs. Although cisplatin is one of the most widely used antineoplastic compounds worldwide [3], acting through covalent binding to DNA, its severe side effects and acquired resistance (e.g., nephrotoxicity) have led to a search for second- and third-generation $\mathrm{Pt}(\mathrm{II})$ agents, aiming at an improved cytotoxic profile coupled to a lower toxicity. Polynuclear Pt(II) chelates with polyamines as bridging ligands, in particular, have lately been the target of intense research due to the recognised enhancement of their antineoplastic effect in comparison to the currently used drugs [4-13]. In fact, many of these new generation $\mathrm{Pt}(\mathrm{II})$ compounds were found to yield DNA adducts displaying long-distance intra- and interstrand cross-links, not available to the conventional mononuclear platinum compounds previously known. However, the exact nature of the mechanisms involved, at a molecular level, is still unknown, 
which highlights the relevance of gathering structural information on this kind of systems in order to understand their biological behaviour.

Some of the ligands associated to this kind of polynuclear chelates are the biogenic triand tetramines spermidine $\left(\mathrm{H}_{2} \mathrm{~N}\left(\mathrm{CH}_{2}\right)_{3} \mathrm{NH}\left(\mathrm{CH}_{2}\right)_{4} \mathrm{NH}_{2}\right)$ and spermine $\left(\mathrm{H}_{2} \mathrm{~N}\left(\mathrm{CH}_{2}\right)_{3} \mathrm{NH}\left(\mathrm{CH}_{2}\right)_{4} \mathrm{NH}\right.$ $\left.\cdot\left(\mathrm{CH}_{2}\right)_{3} \mathrm{NH}_{2}\right)$, which play key physiological roles in cell growth and differentiation in eukaryotic organisms. With a view to fully characterise the conformational preferences of these systems and relate them to their anticancer activity, coordination compounds with smaller linear diamines such as 1,2diaminoethane $\left(\mathrm{H}_{2} \mathrm{~N}\left(\mathrm{CH}_{2}\right)_{2} \mathrm{NH}_{2}\right.$, en) and 1,3-diaminopropane $\left(\mathrm{H}_{2} \mathrm{~N}\left(\mathrm{CH}_{2}\right)_{3} \mathrm{NH}_{2}\right.$, dap) may be used, as good models of the larger complexes (which comprise identical moieties to $\operatorname{Pt}(\mathrm{en}) \mathrm{Cl}_{2}$ or $\operatorname{Pt}(\mathrm{dap}) \mathrm{Cl}_{2}$ ).

The use of vibrational spectroscopy-Fourier transform infrared (FTIR), Raman, and inelastic neutron scattering (INS) - is a reliable and accurate procedure for this kind of studies. INS, in particular, is a well-suited technique to probe hydrogenous compounds such as the one presently investigated, and it yields complementary information to that obtained from Raman and FTIR since it allows to detect some low-frequency modes unavailable to these optical methods. Actually, the neutron scattering crosssection of an atom $(\sigma)$ is characteristic of that atom and independent of its chemical environment. Since the value for hydrogen ( 80 barns) far exceeds that of all other elements ( $c a .5$ barns), the vibrations involving a significant hydrogen displacement $\left(u_{i}\right)$ dominate the INS spectra. For a mode at a given energy $\nu_{i}$, the intensity from a powdered sample obeys the simplified relationship:

$$
S_{i}^{\bullet}\left(Q^{2}, v_{i}\right)=\frac{\left(Q^{2} u_{i}^{2}\right) \sigma}{3} \exp \left(-\frac{Q^{2} \alpha_{i}^{2}}{3}\right)
$$

where $Q\left(\AA^{-1}\right)$ is the momentum transferred from the neutron to the sample and $\alpha_{i}(\AA)$ is related to a weighted sum of all the displacements of the atom. Thus, not only the energies of the vibrational transitions (the eigenvalues, $\nu_{i}$ ) but also the atomic displacements (the eigenvectors, $u_{i}$ ) are available from experimental observation. Furthermore, as the spectral intensities can be quantitatively compared with those calculated theoretically, it is possible to link molecular geometry (calculated data) with the experimental spectroscopic features, thus attaining a consistent conformation for the systems under study.

The present work reports a vibrational spectroscopic analysis of the $\mathrm{Pt}(\mathrm{dap}) \mathrm{Cl}_{2}$ chelate (Figure 1), in the light of quantum mechanical calculations using the density functional density (DFT) approach and effective core potentials (ECPs) for representing the metal. A complete spectral assignment of the complex was achieved, since all vibrational spectroscopic techniques were available for this study.

\section{Experimental}

\subsection{Synthesis}

$\mathrm{Pt}$ (dap) $\mathrm{Cl}_{2}$ (dap $=1$, 3-diaminopropane) was synthesised according to an optimised procedure, based on a previously reported method for $\mathrm{Pt}(\mathrm{en}) \mathrm{Cl}_{2}$ [14].

Briefly, $2 \mathrm{mmol}$ of $\mathrm{K}_{2} \mathrm{PtCl}_{4}$ were dissolved in $12.5 \mathrm{~mL}$ of $\mathrm{HCl}-0.1 \mathrm{M}$, and a solution containing $2 \mathrm{mmol}$ of dap in $75 \mathrm{~mL}$ of $\mathrm{HCl}-0.05 \mathrm{M}$ was added dropwise, under continuous stirring, at $60^{\circ} \mathrm{C}$, for $c a$. 


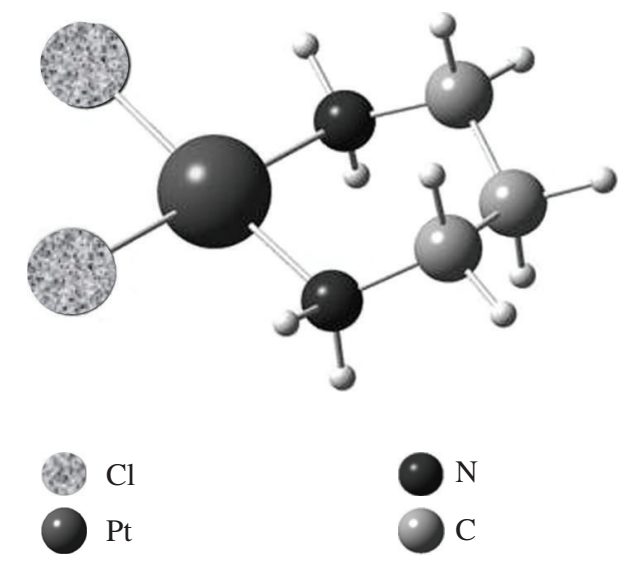

Figure 1: Calculated (mPW1) lowest energy geometry for the $\mathrm{Pt}(\mathrm{dap}) \mathrm{Cl}_{2}$ complex.

2 hours. Upon standing overnight, a dark yellow powder of the complex was formed, which was filtered and washed repeatedly with acetone, yield $=29.7 \%$.

\subsection{Quantum Mechanical Calculations}

Quantum mechanical calculations were performed for $\mathrm{Pt}(\mathrm{dap}) \mathrm{Cl}_{2}$, on Gaussian 03 [19] — both geometry optimisation and calculation of the harmonic vibrational frequencies-within the density functional theory (DFT) approach, at a level which was previously shown by the authors to be the best choice for describing this type of $\mathrm{Pt}(\mathrm{II})$-amine complexes since it presents the finest compromise between accuracy and computational demands $[16,17]$. The mPW1PW method, which comprises a modified version of the exchange term of Perdew-Wang and the Perdew-Wang 91 correlation functional [20, 21], was used, along with the split valence basis set $6-31 G^{*}[22]$, for all atoms except for the metal. Pt(II) was represented by the relativistic effective core potentials of Hay and Wadt [23] (G03W keyword LANL2DZ), $n=5$ and $n=6$ being considered as valence electron shells.

Molecular geometries were fully optimised by the Berny algorithm, using redundant internal coordinates [24]: the bond lengths to within $c a .0 .1 \mathrm{pm}$ and the bond angles to within $c a .0 .1^{\circ}$. The final root-mean-square (rms) gradients were always less than $3 \times 10^{-4}$ hartree $\cdot$ bohr $^{-1}$ or hartree $\cdot$ radian $^{-1}$. No geometrical constraints were imposed on the molecule. The harmonic vibrational wavenumbers, as well as Raman activities and infrared intensities, were obtained at the same theory level as the geometry optimisation procedure.

Simulation of the INS spectra (both the theoretical transition intensities and wavenumbers) was carried out with the dedicated aCLIMAX program [25].

\subsection{Vibrational Spectroscopy}

The Fourier transform infrared (FTIR) spectrum was recorded in a Bruker Optics Vertex 70 FTIR spectrometer, in the range $400-4000 \mathrm{~cm}^{-1}$, using $\mathrm{KBr}$ disks (ca. $1 \%$ (w/w)), a $\mathrm{KBr}$ beamsplitter, and 
a liquid nitrogen cooled Mercury Cadmium Telluride (MCT) detector. 60 scans were collected, with a $2 \mathrm{~cm}^{-1}$ resolution, the error in wavenumbers being estimated to be less than $1 \mathrm{~cm}^{-1}$.

The Raman spectrum were obtained at room temperature, in a triple monochromator Jobin-Yvon T64000 Raman system (focal distance $0.640 \mathrm{~m}$, aperture $f / 7.5$ ) equipped with holographic gratings of 1800 grooves $\cdot \mathrm{mm}^{-1}$. The premonochromator stage was used in the subtractive mode. The detection system was a liquid nitrogen cooled nonintensified $1024 \times 256$ pixel $\left(1^{\prime \prime}\right)$ charge coupled device (CCD) chip. The $514.5 \mathrm{~nm}$ line of an $\mathrm{Ar}^{+}$laser (Coherent, model Innova 300-05) was used as the excitation radiation, providing $\mathrm{ca} .40 \mathrm{~mW}$ at the sample position. A $90^{\circ}$ geometry between the incident radiation and the collecting system was employed. The entrance slit was set to $100 \mu \mathrm{m}$, and the slit between the premonochromator and the spectrograph was $400 \mu \mathrm{m}$. A spectrum was also obtained using the tripple additive mode and a detector assembly containing a thermoelectrically colled Hamamatsu photomultiplier tube, in order to detect the lowest frequency bands.

Samples were sealed in Kimax glass capillary tubes of $0.8 \mathrm{~mm}$ inner diameter. Under the abovementioned conditions, the error in wavenumbers was estimated to be within $1 \mathrm{~cm}^{-1}$.

The INS data was collected at the ISIS-pulsed neutron source of the Rutherford Appleton Laboratory (UK), on the TOSCA spectrometer. This is an indirect geometry time-of-flight, highresolution ( $(\Delta E / E) c a .1 .25 \%)$, broad-range spectrometer [26]. The solid compound (ca. $500 \mathrm{mg}$ ) was wrapped in aluminium foil to make a $4 \times 4 \mathrm{~cm}$ sachet, which filled the beam and placed in a thinwalled aluminium can. Data was recorded at $20 \mathrm{~K}$, in the energy range between 2 to $500 \mathrm{meV}$ (16 to $4000 \mathrm{~cm}^{-1}$ ), and converted to the conventional scattering law, $S(Q, \nu)$ versus energy transfer (in $\mathrm{cm}^{-1}$ ) through standard programs.

\section{Results and Discussion}

Figure 1 represents the most stable geometry calculated for the newly synthesised $\mathrm{Pt}(\mathrm{dap}) \mathrm{Cl}_{2}$ chelate. This compound belongs to the $\mathrm{C}_{\mathrm{S}}$ point group and displays 48 vibrational modes -26 with $\mathrm{A}^{\prime \prime}$ symmetry and 22 with $\mathrm{A}^{\prime \prime}$ symmetry-all Raman and infrared active.

The vibrational spectra obtained for $\mathrm{Pt}(\mathrm{dap}) \mathrm{Cl}_{2}$ are comprised in Figures 2 and 3. The use of all vibrational techniques-FTIR, Raman and INS - allowed to observe virtually all the modes of the molecule and to achieve a complete assignment of its vibrational pattern (Table 1). Special attention was paid to spectral regions comprising particular vibrations which can be considered as a fingerprint of this kind of complexes: (i) the $\mathrm{Cl}-\mathrm{Pt}-\mathrm{Cl}$ and $\mathrm{N}-\mathrm{Pt}-\mathrm{N}$ deformations and stretchings; (ii) the vibrations associated to the diamine ligand, especially $\delta\left(\mathrm{NH}_{2}\right)$ and $\nu\left(\mathrm{NH}_{2}\right)$, which reflect the chelating ability of this particular bidentate moiety.

Interpretation of the experimental data was assisted by the predicted spectra obtained from the quantum mechanical calculations, as well as by comparison with the results previously obtained for cisplatin and analogous complexes [16, 18, 27], and the free diamine ligand [28]. A quite good agreement was found between the experimental and calculated vibrational data (Figures 2 and 3), namely in the low wavenumber region. Scaling of the calculated values was carried out, in order to correct for the known overestimation of the calculated harmonic vibrational frequencies relative to the experimental ones, mainly above $700 \mathrm{~cm}^{-1}$, due to the neglect of anharmonicity effects in the theoretical treatment. As there are no reported scaling methodologies for this type of inorganic (Pt-based) systems, and since the widely used scaling factors developed by Merrick et al. [15] are recommended for organic compounds 


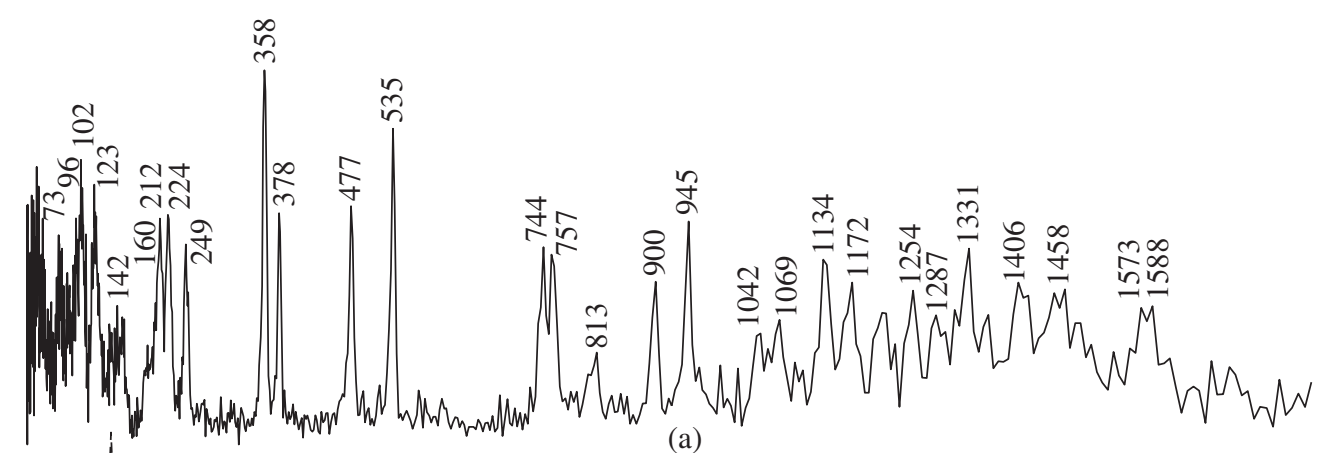

(a)

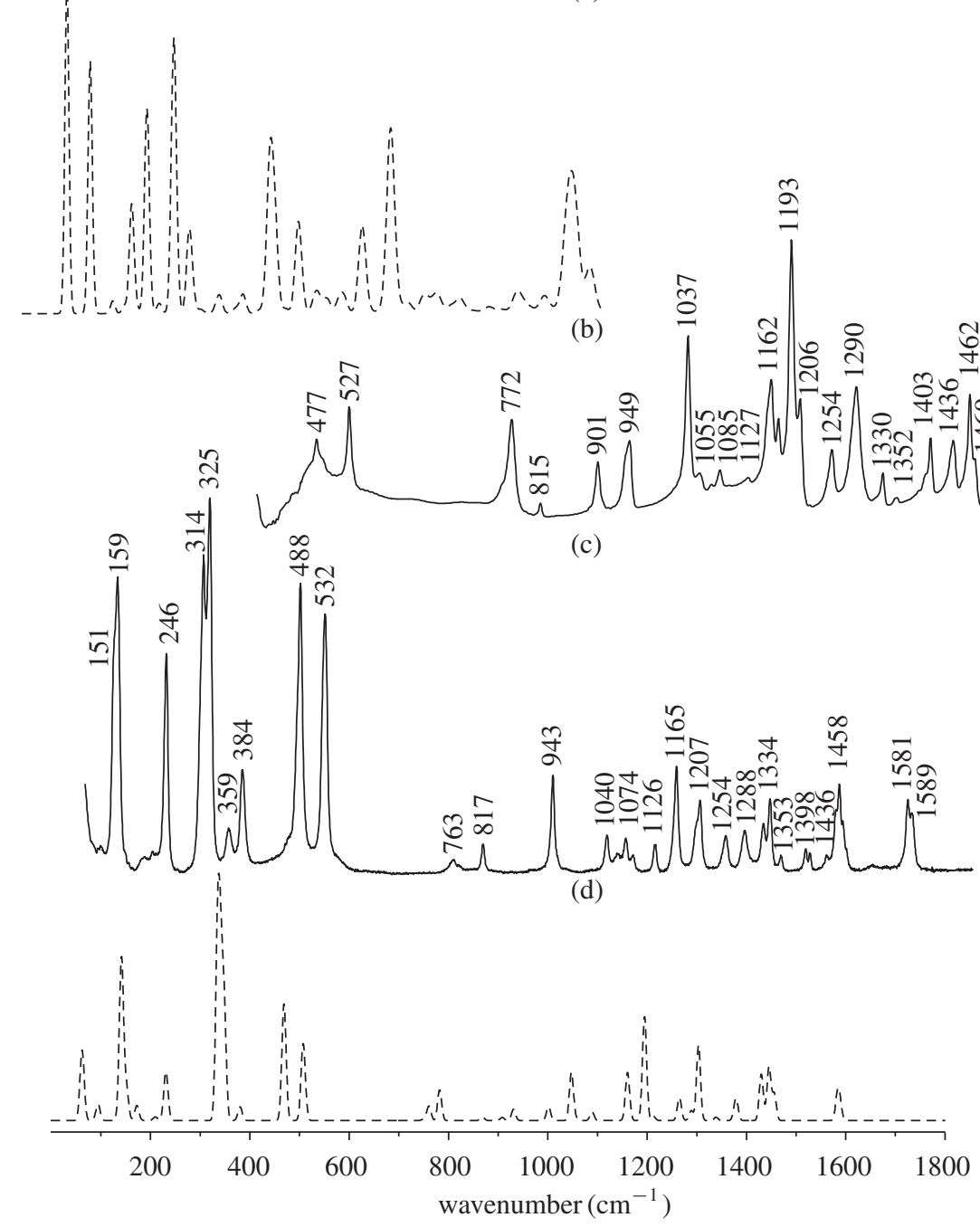

(e)

Figure 2: Vibrational spectra for $\operatorname{Pt}(\operatorname{dap}) \mathrm{Cl}_{2}\left(0-1800 \mathrm{~cm}^{-1}\right)$ : Experimental (a) and calculated (b) INS; experimental FTIR (c) and Raman (d) (double-subtractive mode and CCD detector); calculated Raman (e). 


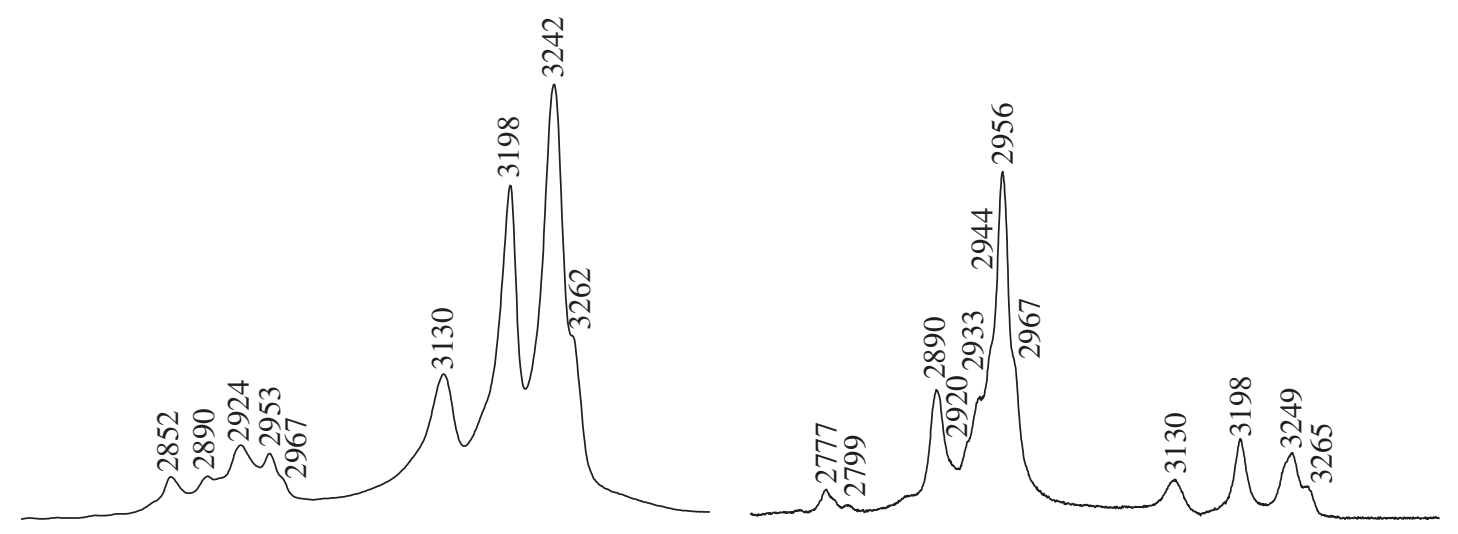

(a)

(b)

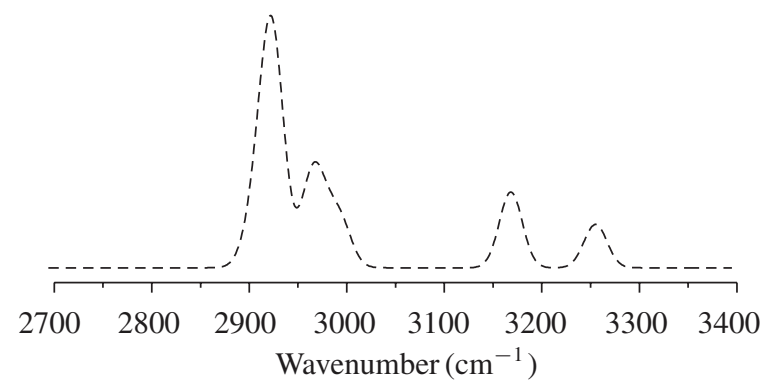

(c)

Figure 3: Optical vibrational spectra for $\mathrm{Pt}(\mathrm{dap}) \mathrm{Cl}_{2}\left(2700-3400 \mathrm{~cm}^{-1}\right)$ : Experimental FTIR (a) and Raman (b) (double-subtractive mode and CCD detector); calculated Raman (c).

only, a four-factor scaling scheme (considering different frequency sets) was applied for $\mathrm{Pt}(\mathrm{dap}) \mathrm{Cl}_{2}$ (Table 1): Merrick's factor of 0.9499 (for the theory level presently used) for the frequencies between 700 and $3150 \mathrm{~cm}^{-1}$ (assigned to the ligand); the value previously determined by the authors for cisplatin [16] for the amine stretching modes (above $3000 \mathrm{~cm}^{-1}$ ) -0.920 ; two factors presently optimised for the deformations of the amine bound to the metal- 0.933 for $\delta\left(\mathrm{NH}_{2}\right)$ and 0.986 for $\omega\left(\mathrm{NH}_{2}\right)$ and $\rho\left(\mathrm{NH}_{2}\right)$.

A red shift of the amine scissoring modes, occurring at $1589 / 1581 \mathrm{~cm}^{-1}$ (Raman), $1586 \mathrm{~cm}^{-1}$ (FTIR) and 1588/1573 $\mathrm{cm}^{-1}$ (INS), was detected relative to the free diaminopropane ligand and similar linear alkylamines, which displays a typical $\mathrm{NH}_{2}$ scissoring vibration centered at $1619 \mathrm{~cm}^{-1}$ [28]. This is anticipated by the metal chelate effect, that leads to an anchoring of the otherwise conformationally free amine groups. Furthermore, there is a significant narrowing of the signals associated to the amine groups upon $\mathrm{Pt}(\mathrm{II})$-coordination.

A well-defined and intense INS band appears at $378 \mathrm{~cm}^{-1}$ (Figure 2) as a result of the (NCC) deformation (Table 1). This can be compared to the $\delta$ (NCC) longitudinal mode (LAM1) of the free ligand, occurring at $409 \mathrm{~cm}^{-1}$ [29], the shift to lower frequency in the chelate being due to the metal coordination. The two signals assigned to the (N-Pt-N) symmetric and antisymmetric stretching modes of the diaminopropane complex display a larger separation than for cisplatin (45-60 versus $16-20 \mathrm{~cm}^{-1}$, Table 1), most probably due to the significantly lower flexibility of the diamine bidentate chelate. 
Table 1: Experimental and calculated vibrational wavenumbers $\left(\mathrm{cm}^{-1}\right)$ for $\operatorname{Pt}(\operatorname{dap}) \mathrm{Cl}_{2}$.

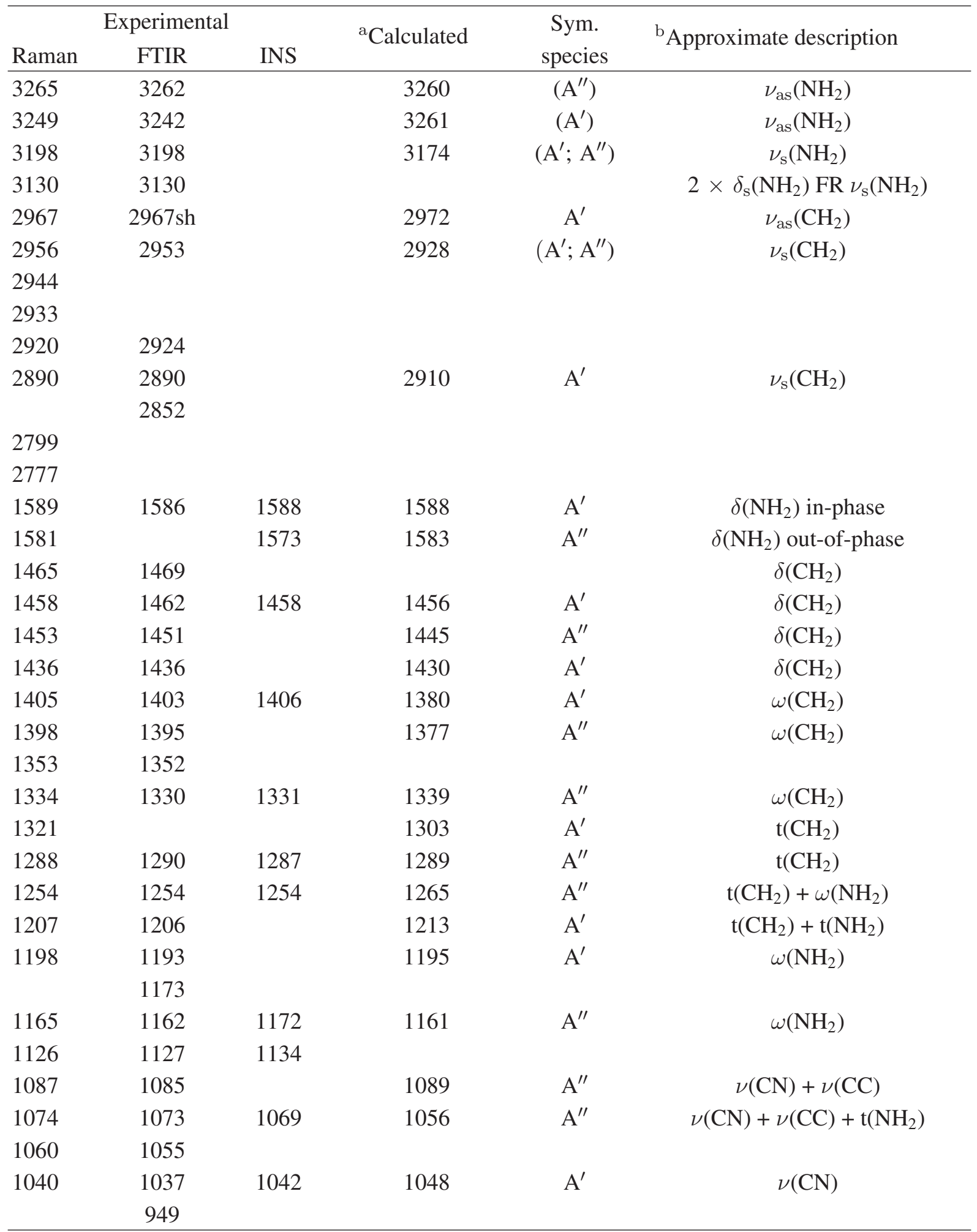


Table 1: Continued.

\begin{tabular}{|c|c|c|c|c|c|}
\hline Raman & $\begin{array}{c}\text { xperimer } \\
\text { FTIR }\end{array}$ & INS & ${ }^{\mathrm{a} C a l c u l a t e d}$ & $\begin{array}{c}\text { Sym. } \\
\text { species }\end{array}$ & ${ }^{\mathrm{b}}$ Approximate description \\
\hline \multirow[t]{2}{*}{943} & $943 \mathrm{sh}$ & 945 & 931 & $\mathrm{~A}^{\prime \prime}$ & $\nu(\mathrm{CN})+\nu(\mathrm{CC})$ \\
\hline & 901 & 900 & 909 & $\mathrm{~A}^{\prime}$ & $\rho\left(\mathrm{CH}_{2}\right)$ \\
\hline 817 & 815 & 813 & 783 & $\mathrm{~A}^{\prime}$ & $\nu(\mathrm{CC})$ \\
\hline 774 & 772 & & & & $\rho\left(\mathrm{CH}_{2}\right)$ \\
\hline \multirow[t]{2}{*}{763} & $758 \mathrm{sh}$ & 757 & 761 & $\mathrm{~A}^{\prime}$ & $\rho\left(\mathrm{NH}_{2}\right)$ \\
\hline & & 744 & 752 & $A^{\prime \prime}$ & $\rho\left(\mathrm{NH}_{2}\right)$ \\
\hline $\begin{array}{l}532 \\
\left({ }^{c} 508\right)\end{array}$ & 527 & $\begin{array}{c}535 \\
\left({ }^{c} 505\right)\end{array}$ & 510 & $\mathrm{~A}^{\prime \prime}$ & $\nu_{\text {as }}(\mathrm{N}-\mathrm{Pt}-\mathrm{N})$ \\
\hline $\begin{array}{l}488 \\
\left({ }^{c} 524\right)\end{array}$ & $486 \mathrm{sh}$ & & 508 & $\mathrm{~A}^{\prime}$ & $\nu_{\mathrm{s}}(\mathrm{N}-\mathrm{Pt}-\mathrm{N})+\delta(\mathrm{CCC})$ \\
\hline $481 \mathrm{sh}$ & 477 & $\begin{array}{c}477 \\
\text { (c521) }\end{array}$ & 470 & $\mathrm{~A}^{\prime}$ & $\delta(\mathrm{CCC})+\nu_{\mathrm{s}}(\mathrm{N}-\mathrm{Pt}-\mathrm{N})$ \\
\hline 384 & & 378 & 381 & $\mathrm{~A}^{\prime \prime}$ & $\delta(\mathrm{NCC})$ \\
\hline 359 & & 358 & 349 & $\mathrm{~A}^{\prime}$ & $\delta(\mathrm{CCC})+\nu_{\mathrm{S}}(\mathrm{Cl}-\mathrm{Pt}-\mathrm{Cl})$ \\
\hline \multicolumn{6}{|l|}{$d_{325}$} \\
\hline d 314 & & & 336 & $\mathrm{~A}^{\prime \prime}$ & $\nu_{\mathrm{as}}(\mathrm{Cl}-\mathrm{Pt}-\mathrm{Cl})$ \\
\hline \multirow[t]{4}{*}{246} & & 249 & 232 & $\mathrm{~A}^{\prime}$ & $\delta_{\mathrm{s}}(\mathrm{N}-\mathrm{Pt}-\mathrm{N})$ \\
\hline & & $\mathrm{d}_{224}$ & & & \\
\hline & & ${ }^{d} 212$ & 211 & $\mathrm{~A}^{\prime \prime}$ & $\gamma(\mathrm{CN}-\mathrm{Pt}-\mathrm{NC})$ out-of-phase \\
\hline & & & 174 & $\mathrm{~A}^{\prime}$ & $\gamma(\mathrm{CN}-\mathrm{Pt}-\mathrm{NC})$ in-phase \\
\hline 159 & & 160 & 153 & $\mathrm{~A}^{\prime \prime}$ & $\delta(\mathrm{N}-\mathrm{Pt}-\mathrm{Cl})$ \\
\hline \multirow[t]{4}{*}{$151 \mathrm{sh}$} & & 142 & 143 & $\mathrm{~A}^{\prime}$ & $\delta(\mathrm{Cl}-\mathrm{Pt}-\mathrm{Cl})$ \\
\hline & & 123 & & & external libration \\
\hline & & 102 & & & external libration \\
\hline & & 96 & 95 & $A^{\prime \prime}$ & e global "torsion" mode \\
\hline 66 & & 73 & 63 & $\mathrm{~A}^{\prime}$ & eglobal "butterfly" mode \\
\hline
\end{tabular}

${ }^{\mathrm{a}}$ At the mPW1 level. Scaled according to: 0.9499 for the bands in the $700-3150 \mathrm{~cm}^{-1}$ range [15]; 0.920 for $\left(\mathrm{NH}_{2}\right)$ [16]; 0.933 for $\delta\left(\mathrm{NH}_{2}\right)$; 0.986 for $\omega\left(\mathrm{NH}_{2}\right)$ and $\rho\left(\mathrm{NH}_{2}\right)$; ${ }^{\mathrm{b}}$ Symbols for vibrational modes: $\delta$-in-plane deformation, $\mathrm{t}$ - $\mathrm{twisting}, \rho-$ rocking, $\omega$-wagging, $\gamma$-out-of-plane deformation, s, as, and a refer to symmetric, antisymmetric, and asymmetric modes, respectively, sh refers to a shoulder; ${ }^{\mathrm{c}}$ For cisplatin $[17,18] ;{ }^{\mathrm{d}}$ Davydov splitting; ${ }^{\mathrm{e}}[18]$.

Furthermore, an inversion is detected between the symmetric and antisymmetric stretching wavenumber values, the latter being observed at higher values for $\mathrm{Pt}(\mathrm{dap}) \mathrm{Cl}_{2}$ as opposed to $\mathrm{Pt}\left(\mathrm{NH}_{3}\right)_{2} \mathrm{Cl}_{2}$, while the former is mixed with the $\delta(\mathrm{CCC})$ mode. Also, cisplatin's typical $\rho\left(\mathrm{NH}_{3}\right)$ feature (centered at $c a$. $790 \mathrm{~cm}^{-1}$ ) is substituted in the diamine chelate by the amine rocking modes, clearly detected by INS at 757 and $744 \mathrm{~cm}^{-1}$ (Table 1). 
A clear splitting of the INS band ascribed to the out-of-plane. out-of-phase (CN-Pt-NC) deformation (212 and $224 \mathrm{~cm}^{-1}$, Figure 2), predicted as a single feature at $211 \mathrm{~cm}^{-1}$ (Table 1), may be attributed to a Davydov splitting, reflecting the presence of more than one molecular entity in the crystalline unit cell for this sample. In fact, this may lead to a doubling of the spectral features due to the occurrence of crystallographically inequivalent conformations. This was previously detected by INS in $n$-alkanes [30] and linear alkyl-polyamines [31]. A similar splitting was verified for the $\nu(\mathrm{Cl}-\mathrm{Pt}-\mathrm{Cl})$ vibration in $\mathrm{Pt}($ dap $) \mathrm{Cl}_{2}$, calculated at $336 \mathrm{~cm}^{-1}$ and yielding the 325 and $314 \mathrm{~cm}^{-1}$ experimental bands. These are only detected by Raman, which is a good example of the clear advantage of applying several vibrational techniques to the study of the same system.

The full conformational characterisation of this type of Pt(II)-amine compounds, as suitable models of larger polyamine polynuclear metal complexes, will clarify their mode of action within the cell and help to expose the molecular basis of their cytoxicity, thus contributing for a tailored design of new and more efficient cisplatin-like anticancer agents.

\section{Acknowledgments}

The authors would like thank the financial support from the Portuguese Foundation for Science and Technology_Project PTDC/QUI/66701/2006 (cofinanced by the European Community fund FEDER), PEst-OE/QUI/UI0070/2011, and Ph.D. Fellowship SFRH/BD/72851/2010. The INS work has been supported by the European Commission under the 7th Framework Programme through the Key Action: Strengthening the European Research Area, Research Infrastructures; Contract no.: CP-CSA_INFRA2008-1.1.1 no. 226507-NMI3.

\section{References}

[1] B. Rosenberg, L. Van Camp, and T. Krigas, "Inhibition of cell division in Escherichia coli by electrolysis products from a platinum electrode," Nature, vol. 205, pp. 698-699, 1965.

[2] B. Rosenberg, L. VanCamp, J. E. Trosko, and V. H. Mansour, "Platinum compounds: a new class of potent antitumour agents," Nature, vol. 222, no. 5191, pp. 385-386, 1969.

[3] D. Wang and S. J. Lippard, "Cellular processing of platinum anticancer drugs," Nature Reviews Drug Discovery, vol. 4, no. 4, pp. 307-320, 2005.

[4] L. R. Kelland and N. P. Farrell, "Polynuclear charged platinum compounds as a new class of anticancer agents: toward a new paradigm," in Platinum-Based Drugs in Cancer Therapy, Cancer Drug Discovery and Development, pp. 321-338, Humana Press, Totowa, NJ, USA, 2000.

[5] K. Chválová, J. Kašpárková, N. Farrell, and V. Brabec, "Deoxyribonuclease I footprinting reveals different DNA binding modes of bifunctional platinum complexes," FEBS Journal, vol. 273, no. 15, pp. 3467-3478, 2006.

[6] C. Mitchell, P. Kabolizadeh, J. Ryan et al., "Low-dose BBR3610 toxicity in colon cancer cells is p53-independent and enhanced by inhibition of epidermal growth factor receptor (ERBB1)phosphatidyl inositol 3 kinase signaling," Molecular Pharmacology, vol. 72, no. 3, pp. 704-714, 2007.

[7] A. Hegmans, J. Kasparkova, O. Vrana, L. R. Kelland, V. Brabec, and N. P. Farrell, "Amidebased prodrugs of spermidine-bridged dinuclear platinum. Synthesis, DNA binding, and biological activity," Journal of Medicinal Chemistry, vol. 51, no. 7, pp. 2254-2260, 2008. 
[8] M. P. M. Marques, T. Girão, M. C. Pedroso De Lima, A. Gameiro, E. Pereira, and P. Garcia, "Cytotoxic effects of metal complexes of biogenic polyamines. I. Platinum(II) spermidine compounds: prediction of their antitumour activity," Biochimica et Biophysica Acta, vol. 1589, no. 1, pp. 63-70, 2002.

[9] L. J. Teixeira, M. Seabra, E. Reis et al., "Cytotoxic activity of metal complexes of biogenic polyamines: polynuclear platinum(II) chelates," Journal of Medicinal Chemistry, vol. 47, no. 11, pp. 2917-2925, 2004.

[10] S. M. Fiuza, A. M. Amado, P. J. Oliveira, V. A. Sardão, L. A. E. Batista de Carvalho, and M. P. M. Marques, "Pt(II) vs Pd(II) polyamine complexes as new anticancer drugs: a structure-activity study," Letters in Drug Design \& Discovery, vol. 3, no. 3, pp. 149-151, 2006.

[11] S. M. Fiuza, J. Holy, L. A. E. Batista de Carvalho, and M. P. M. Marques, "Biologic activity of a dinuclear Pd(II)-spermine complex toward human breast cancer," Chemical Biology \& Drug Design, vol. 77, no. 6, pp. 477-488, 2011.

[12] T. Muchova, S. Quintal, N. Farrell, V. Brabec, and J. Kasparkova, "Antitumor bifunctional dinuclear $\mathrm{Pt}^{I I}$ complex BBR3535 forms interduplex DNA cross-links under molecular crowding conditions," Journal Biological Inorganic Chemistry, vol. 17, no. 2, pp. 239-245, 2012.

[13] S. Komeda, "Unique platinum-DNA interactions may lead to more effective platinum-based antitumor drugs," Metallomics, vol. 3, no. 7, pp. 650-655, 2011.

[14] R. Roulet and R. Ernst, "Substitution reactions in tetrachloropalladate (II) ion with diamines. 1. Ethylenediamine," Helvetica Chimica Acta, vol. 54, no. 8, pp. 2357-2362, 1971.

[15] J. P. Merrick, D. Moran, and L. Radom, "An evaluation of harmonic vibrational frequency scale factors," The Journal of Physical Chemistry A, vol. 111, no. 45, pp. 11683-11700, 2007.

[16] S. M. Fiuza, A. M. Amado, M. P. M. Marques, and L. A. E. Batista de Carvalho, "Use of effective core potential calculations for the conformational and vibrational study of platinum(II) anticancer drugs. cis-diamminedichloroplatinum(II) as a case study," The Journal of Physical Chemistry A, vol. 112, no. 14, pp. 3253-3259, 2008.

[17] A. M. Amado, S. M. Fiuza, M. P. M. Marques, and L. A. E. Batista de Carvalho, "Conformational and vibrational study of platinum(II) anticancer drugs: cis-diamminedichloroplatinum (II) as a case study," The Journal of Chemical Physics, vol. 127, no. 18, Article ID 185104, 2007.

[18] L. A. E. Batista de Carvalho, M. P. M. Marques, C. Martin, S. F. Parker, and J. Tomkinson, "Inelastic neutron scattering study of PtII complexes displaying anticancer properties," ChemPhysChem, vol. 12, no. 7, pp. 1334-1341, 2011.

[19] M. J. Frisch, G. W. Trucks, H. B. Schlegel et al., "GAUSSIAN 03 (Revision D.01)," Gaussian, Wallingford, Conn, USA, 2004.

[20] C. Adamo and V. Barone, "Exchange functionals with improved long-range behavior and adiabatic connection methods without adjustable parameters: the mPW and mPW1PW models," The Journal of Chemical Physics, vol. 108, no. 2, pp. 664-675, 1998.

[21] J. P. Perdew, K. Burke, and Y. Wang, "Generalized gradient approximation for the exchangecorrelation hole of a many-electron system," Physical Review B, vol. 54, no. 23, pp. 16533-16539, 1996.

[22] P. C. Hariharan and J. A. Pople, "The influence of polarization functions on molecular orbital hydrogenation energies," Theoretica Chimica Acta, vol. 28, no. 3, pp. 213-222, 1973.

[23] P. J. Hay and W. R. Wadt, "Ab initio effective core potentials for molecular calculations. Potentials for the transition metal atoms Sc to Hg," The Journal of Chemical Physics, vol. 82, no. 1, pp. 270-283, 1985.

[24] C. Peng, P. Y. Ayala, H. B. Schlegel, and M. J. Frisch, "Using redundant internal coordinates to optimize equilibrium geometries and transition states," Journal of Computational Chemistry, vol. 17, no. 1, pp. 49-56, 1996. 
[25] A. J. Ramirez-Cuesta, "aCLIMAX 4.0.1, the new version of the software for analyzing and interpreting INS spectra," Computer Physics Communications, vol. 157, no. 3, pp. 226-238, 2004.

[26] http://www.isis.stfc.ac.uk/.

[27] M. P. M. Marques, L. A. E. Batista de Carvalho, and J. Tomkinson, "Conformational study of new Pd(II) polyamine complexes displaying anticancer activity (RB520092)," Annual Report, The Rutherford Appleton Laboratory, ISIS Facility, 2006.

[28] S. R. O. Mendes, M. P. M. Marques, and L. A. E. Batista de Carvalho, in preparation.

[29] M. P. M. Marques, L. A. E. Batista de Carvalho, and J. Tomkinson, "Study of biogenic and $\alpha, \omega-$ polyamines by combined inelastic neutron scattering and Raman spectroscopies and by Ab initio molecular orbital calculations," The Journal of Physical Chemistry A, vol. 106, no. 11, pp. 24732482, 2002.

[30] J. Tomkinson, S. F. Parker, D. A. Braden, and B. S. Hudson, "Inelastic neutron scattering spectra of the transverse acoustic modes of the normal alkanes," Physical Chemistry Chemical Physics, vol. 4, no. 5, pp. 716-721, 2002.

[31] L. A. E. Batista de Carvalho, M. P. M. Marques, and J. Tomkinson, "Transverse acoustic modes of biogenic and $\alpha, \omega$-polyamines: a study by inelastic neutron scattering and raman spectroscopies coupled to DFT calculations," The Journal of Physical Chemistry A, vol. 110, no. 47, pp. 1294712954, 2006. 


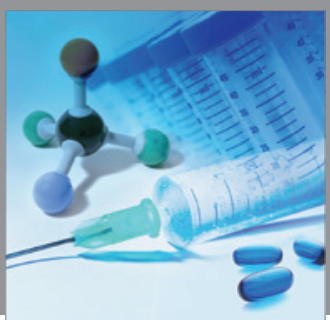

International Journal of

Medicinal Chemistry

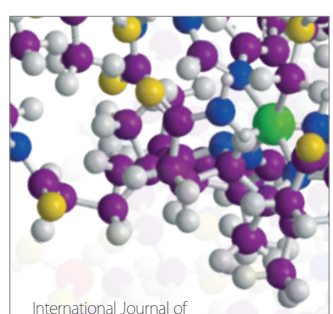

Carbohydrate Chemistry

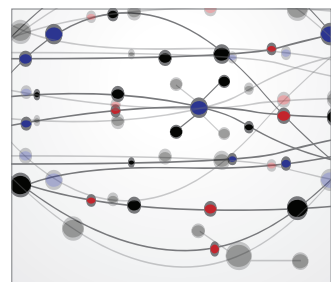

The Scientific World Journal
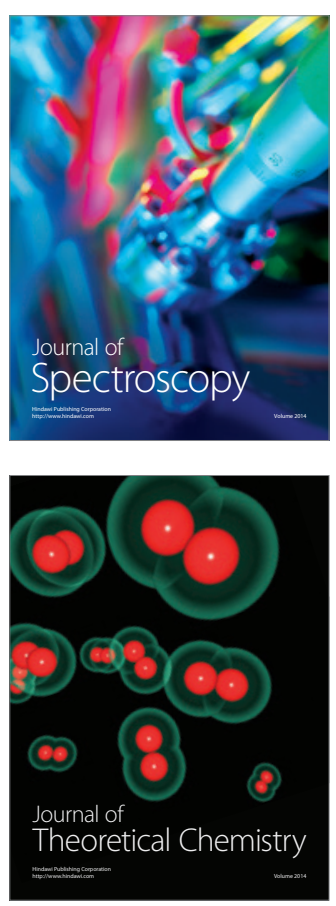
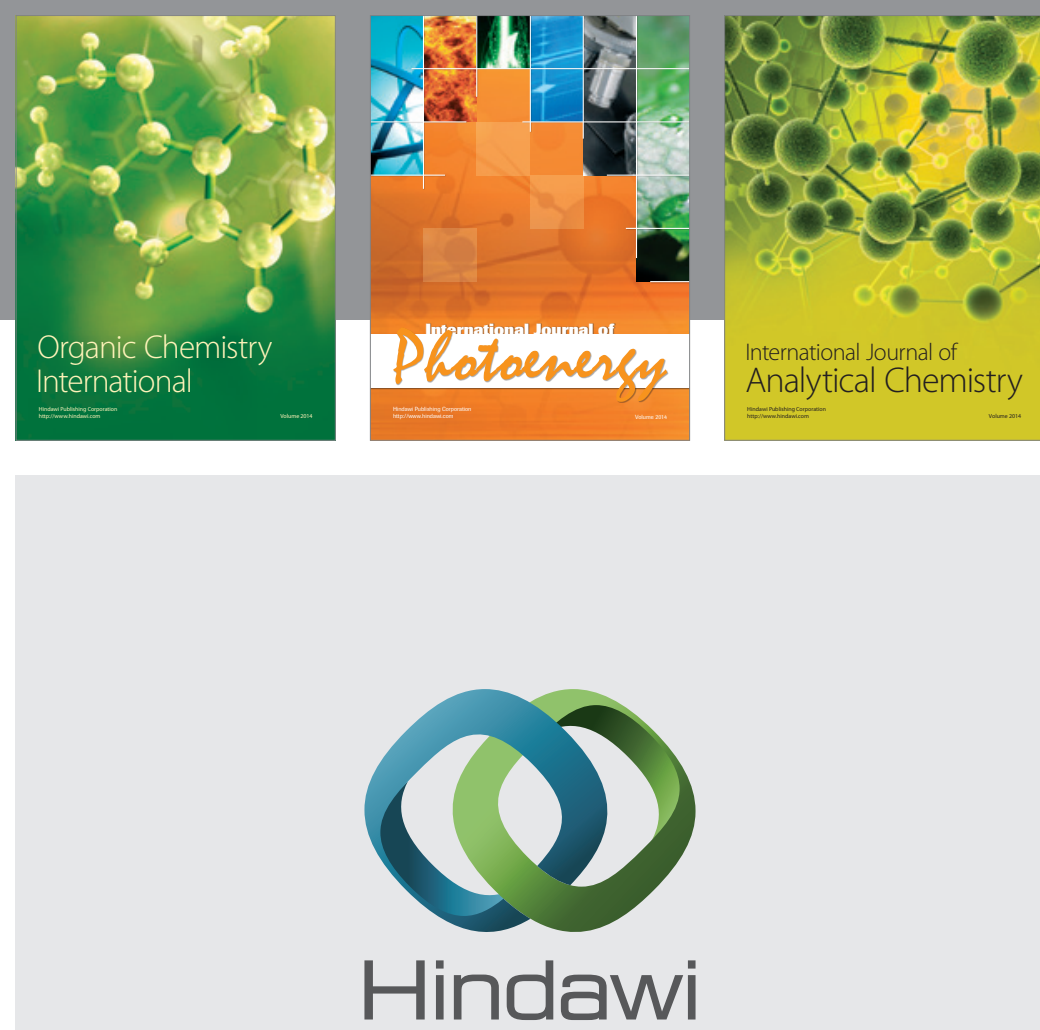

Submit your manuscripts at

http://www.hindawi.com
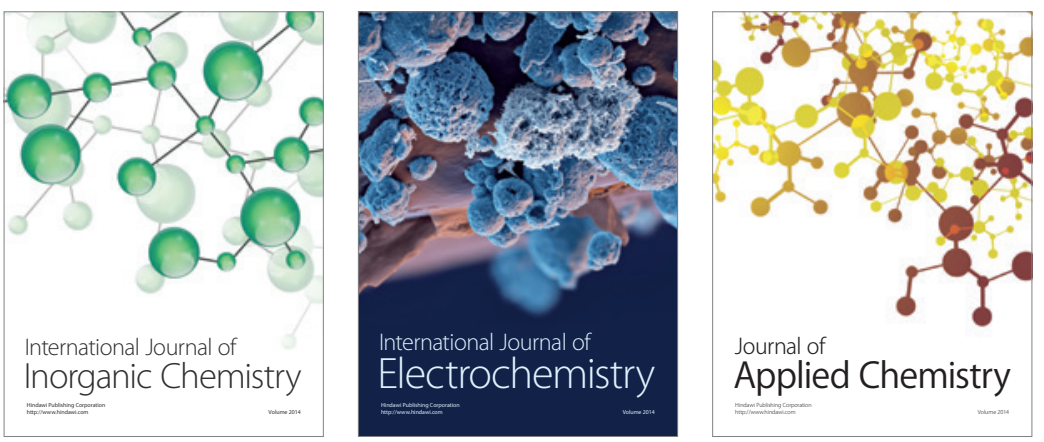

Journal of

Applied Chemistry
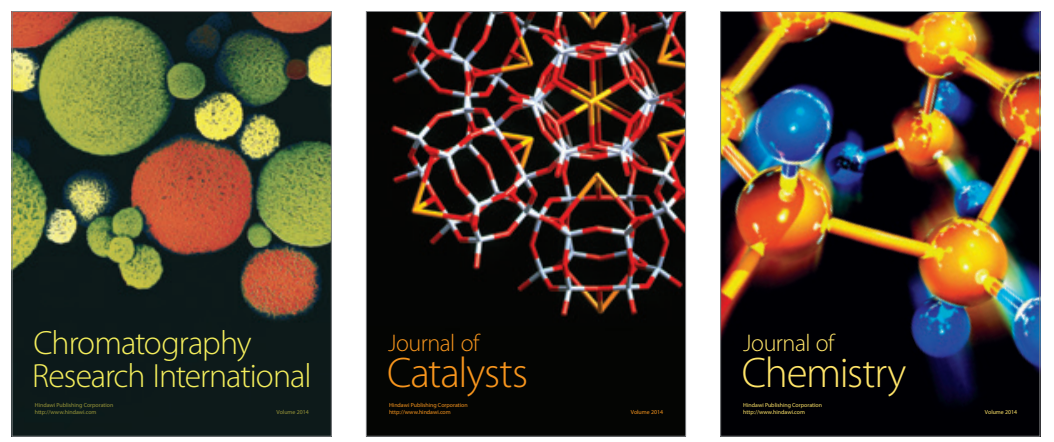
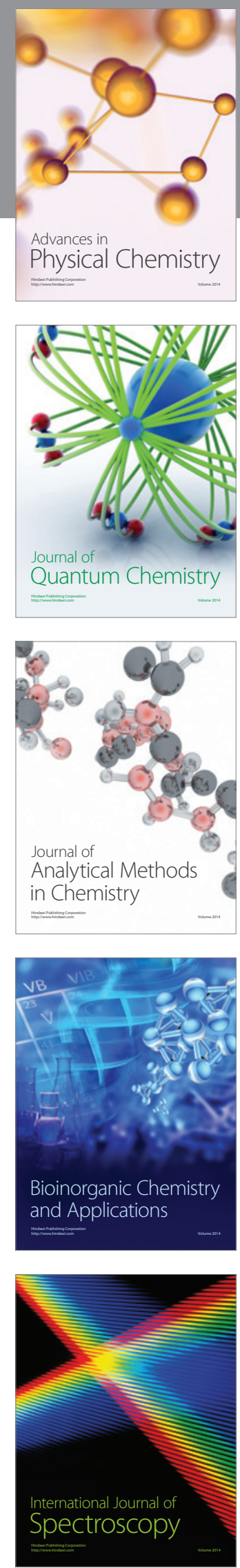